\title{
The Effect of either Aerobic Exercise Training or Chrysin Supplementation on Mitochondrial Biogenesis in Skeletal Muscle of High Fat Diet-Induced Obese Mice
}

\author{
Kyung-Il Kim ${ }^{1}$, Sang-Min An ${ }^{2}$, Hee-Geun Park ${ }^{1}$, Kwang-moo Lee ${ }^{3}$, Wang-Lok Lee ${ }^{1}$ \\ ${ }^{1}$ Department of Sport Science, Chungnam National University, Daejeon; ${ }^{2}$ Department of Sport and Leisure Studies, Korea University, Sejong; ${ }^{3}$ Department of Physical \\ Education, Gongju National University of Education, Gongju, Korea
}

PURPOSE: The purpose of this study was to investigate the effects of either aerobic exercise or resveratrol supplementation on mitochondrial biogenesis in skeletal muscle of the high fat diet-induced obese mice.

METHODS: C57BL/6 (4 weeks aged) male mice were divided into four groups; normal diet group (NC, $\mathrm{n}=10$ ), high fat diet group $(\mathrm{HC})$, high fat diet group with chrysin supplementation $(\mathrm{HCh}, \mathrm{n}=10)$ and high fat diet with exercise group $(\mathrm{HE}, \mathrm{n}=10)$. Aerobic exercise was performed on a treadmill exercise for 40-60 min/day at 10-14 m/min, 0\% grade, 4 days/week for 16 weeks. Chrysin (50 mg/ $\mathrm{kg}$ body weight) daily administrated orally at 4 days/week frequency for 16 weeks.

RESULTS: The gene expression of SIRT-3 in HE group was significantly increased compared to that in HC group ( $p<.05)$. Also, PGC-1 $\alpha$ and COX-IV mRNA levels in the HE group were the highest among all groups $(p<.05)$.

CONCLUSIONS: It seems that high fat diet-induced obese dose not affect mitochondrial biogenesis gene expression in skeletal muscle. However aerobic exercise training could increase the mitochondrial biogenesis gene expression of skeletal muscle in high fat dietinduced obese mice. These findings suggest that only aerobic exercise not chrysin supplementation has a positive effect on mitochondrial biogenesis in the skeletal muscle in high fat diet-induced obese mice.

Key words: Aerobic exercise, Chrysin, Mitochondrial biogenesis, Obese, Skeletal muscle

\section{INTRODUCTION}

Obesity is characterized by increased storage of fatty acids in an expanded adipose tissue mass and in peripheral tissues [1]. Chronic obesity from lack of physical activity or high fat diet is a cause for cardiovascular disease, metabolic syndrome, arteriosclerosis, type-2 diabetes [2] and mitochondrial dysfunction [3]. Mitochondrial dysfunction is also the cause of a syndrome of metabolic defects that includes hypomagnesemia, hypertension, and hypercholesterolemia [4]. Defective mitochondrial function in muscle can lead to reduced fatty-acid oxidation and inhibition of glucose transport [5].

Mitochondrial biogenesis is regulated by regulatory factors such as
PGC-1 $\alpha$ (peroxisome proliferator-activated receptor- $\gamma$ coactivator $1 \alpha$ ) and NRF-1 (nuclear respiratory factor 1) [6]. PGC-la is involved into mitochondrial oxidative metabolism and the maintenance of glucose and lipid [7]. Also, it is highly related to COX-IV (Cytochrome c oxidase subunit IV), ATP and citrate synthase activity [7-9].

It is known that moderate endurance exercise training improves metabolic and mitochondrial function [10] and regular exercise training improves the function of the mitochondria via the expression of PGC-1a and Tfam (mitochondrial transcription factor A) [11].

SIRT-1 (silent mating type information regulation 2, homolog 1) is activated by the PGC-1a [12] and recent studies have shown that SIRT-3 (silent mating type information regulation 2, homolog 2) exists in the

Corresponding author: Wang-Lok Lee Tel +82-42-821-6458 Fax+82-42-823-0387 E-mail leewldacnu.ac.kr

Received 25 Jun 2019 Revised 17 Sep 2019 Accepted 15 Oct 2019

(a) This is an Open Access article distributed under the terms of the Creative Commons Attribution Non-Commercial License (http://creativecommons.org/licenses/by-nc/4.0/) which permits unrestricted non-commercial use, distribution, and reproduction in any medium, provided the original work is properly cited. 
mitochondria and increases PGC-la that induce mitochondrial biogenesis by regulating mitochondrial number and substrate utilization. In previous studies, Palacios et al. [13] showed that the expression of SIRT-3 was increased in 7-week-old FVB/NJ rats after 6 weeks of wheel-cage exercise. Hokari et al. [14] showed that treadmill running increased the amount of SIRT-3 protein and mitochondria density in the skeletal muscle of the rats. And it has been known that the trained individuals showed a higher number of SIRT-3 proteins and mitochondria compared to sedentary individuals [15]. COX-IV protein plays an important role in aerobic exercise capacity by regulation of mitochondrial oxiative phosphorylation [16-18]. Also, COX-IV is used as an indicator of aerobic exercise performance because it is controlled by PGC-1a that regulate mitochondrial biogenesis and function [19].

Recently, many scientists have used a variety way to treat obesity induced metabolic complication such as caloric restriction and functional nutrition diet. Flavonoids, one of these treat, have been reported for antiinflammatory, antidiabetic, anticancer, neuro-protective and cardio-protective activities [20]. Flavonoids were reported to enhance insulin secretion, promote pancreatic $\beta$-cells proliferation, glucose uptake, and reduce insulin resistance, inflammation and oxidative stress. Chrysin (5,7dihydroxyflavone) is a natural flavonoid contained in many plant extracts, honey and propolis [21,22]. Multiple studies have indicated antioxidant, antihypertensive, antidiabetogenic, and anxiolytic functions [23-26]. Also, chrysin shows promising hepatoprotective and anti-hyperlipidemic effects, which are evidenced by the decreased levels of triglycerides, free fatty acids, total cholesterol, phospholipids, low-density lipoprotein-C, and very low-density lipoprotein- $\mathrm{C}$ and increased levels of high-density lipoprotein-C in the plasma and tissues of hepatotoxicity in rats [27]. Nonetheless, there are only a few studies comparing the effects of exercise training and chrysin supplementation.

Taken together, even if the effect of chrysin has been reported on antioxidant and insulin resistance so on. There is no evidence of chrysin supplementation on mitochondria biogenesis in obese-induced metabol-

Table 1. Formulas of rodent feed

\begin{tabular}{lccccc}
\hline \multirow{2}{*}{ Product } & \multicolumn{2}{c}{ Normal diet } & & \multicolumn{2}{c}{ High-fat diet (D12492) } \\
\cline { 2 - 3 } \cline { 5 - 6 } & $\mathrm{g} \%$ & \%kcal & & $\mathrm{g} \%$ & \%kcal \\
\hline Carbohydrate & 44.2 & 58 & & 26.2 & 20 \\
Protein & 18.6 & 24 & & 26.3 & 20 \\
Fat & 6.2 & 18 & & 34.9 & 60 \\
Total & & 100 & & & 100 \\
$\mathrm{kcal} / \mathrm{g}$ & 3.1 & & & 5.24 & \\
\hline
\end{tabular}

ic complication. In addition, there is little research to our knowledge, comparing the effects of exercise training and chrysin supplementation on high fat diet-induced metabolic complication.

Therefore, the purpose of this study was to analyze the effects of either aerobic exercise or chrysin supplementation on mitochondrial biogenesis in skeletal muscle of high fat diet-induced obese mice.

\section{METHODS}

\section{Animals and diet}

Four-week-old male C57BL/6 (Central Experiment Animal, Korea, $\mathrm{n}=40$ ) mice were housed in cages (5 mice per cage) in a standard experimental laboratory, at a temperature of $22 \pm 2^{\circ} \mathrm{C}$, with $50 \pm 5 \%$ humidity. After a one-week acclimatization period, the mice were fed either a high fat diet (60\% of energy from fat, Orient Bio Inc., \# D12451) or a normal diet (10\% of energy from fat, Orient Bio Inc., \# D12451) ad libitum for 16 weeks (Table 1).

The classification of groups was classified into total four groups such as normal diet group ( $\mathrm{NC}, \mathrm{n}=10)$, high fat diet group (HC), high fat diet group with chrysin supplementation $(\mathrm{HCh}, \mathrm{n}=10)$ and high fat diet with exercise group $(\mathrm{HE}, \mathrm{n}=10)$ and then chrysin supplementation and exercise were applied for 16 weeks. After finishing the treatment (16 weeks for either diet or exercise intervention) for 16 weeks, the gastrocnemius muscles of the animals were collected. The samples of gastrocnemius muscles were mixed before analyzing. All experiments were approved by the Animal Care and Use Committee at the Chungnam National University (CNU-00494).

\section{Chrysin supplements and muscle dissection}

Chrysin supplement purchased from Sigma Aldrich Inc. Chrysin supplement was orally given $50 \mathrm{mg} / \mathrm{kg}$ body weight dissolved in a $0.1 \mathrm{~mL}$ solution of Dimethyl Sulfoxide (DMSO). The supplements were administered orally using a disposable $1 \mathrm{~mL}$ syringe at dose $0.1 \mathrm{~mL}$ per mouse 4 times a week.

All the mice were sacrificed after fasted for 12 hours under anesthesia

Table 2. Exercise protocol

\begin{tabular}{lccc}
\hline \multirow{2}{*}{ Weeks } & \multicolumn{3}{c}{ Treadmill exercise } \\
\cline { 2 - 4 } & Speed $(\mathrm{m} / \mathrm{min})$ & Time $(\mathrm{min})$ & \%VO $_{2}$ max \\
\hline $1-2$ & 10 & 40 & 60 \\
$3-5$ & 12 & 50 & 70 \\
$6-16$ & 14 & 60 & 76 \\
\hline
\end{tabular}


using a mixture ketamine $(80 \mathrm{mg} / \mathrm{kg})$ and xylazine $(10 \mathrm{mg} / \mathrm{kg})$. The gastrocnemius muscle was dissected, weighed and immediately frozen in liquid nitrogen and stored at $-70^{\circ} \mathrm{C}$ until analysis.

\section{Exercise protocol}

Exercise training was performed on a motor treadmill at moderate intensity for 16 weeks, 4 days/week for 40-60 $\mathrm{min} /$ day. The exercise was performed at a speed of $10 \mathrm{~m} / \mathrm{min}$ for $1-2$ weeks, $12 \mathrm{~m} / \mathrm{min}$ for 3-5 weeks and $14 \mathrm{~m} / \mathrm{min}$ for 6-16 weeks. This exercise intensity corresponds to 60$76 \%$ of maximal oxygen uptake [28] all groups were exposed to the same noise and handling as the exercise groups (Table 2).

\section{RNA extraction and RT-PCR}

In order to extract total RNA, $40 \mu \mathrm{g}$ of tissue was put into Trizol (Qiagen, Hilden, Germany) and the tissue was grinded for 20 seconds using a homogenizer, and the homogenized solution prepared from the homogenizer was allowed to stand at room temperature for 5 minutes. Chloroform (Sigma, Missouri, USA) of $200 \mu \mathrm{L}$ was added into this solution, and then the solution was allowed to stand for 3 minutes at room temperature after mixing for 15 seconds so that the chloroform was wholly mixed well, and was centrifuged (13,000 rpm, $4^{\circ} \mathrm{C}, 15$ minutes). The only clear supernatant solution was separated from the centrifuged solution

Table 3. Primer sequences used for Real-time PCR

\begin{tabular}{lll}
\hline Gene & \multicolumn{1}{c}{ Forward } & \multicolumn{1}{c}{ Reverse Primer } \\
\hline GAPDH & GAGAGTGTTTCCTCGTCC & AATGAAGGGGTCGTTGATGG \\
SIRT-1 & GATGACGATGACAGAACGTC & GAATTGTTCGAGGATCGGTG \\
SIRT-3 & AGACTTGGGTCCTCTGAAAC & CTCCCACACAGAGGGATATG \\
PGC-1a & CTGTGTGTCAGAGTGGATTG & GCAGCACACTCTATGTCACT \\
COX-IV & TCTTGGTCTTCCGGTTGC & CTCTGGAAGCCAACATTCTG \\
\hline
\end{tabular}

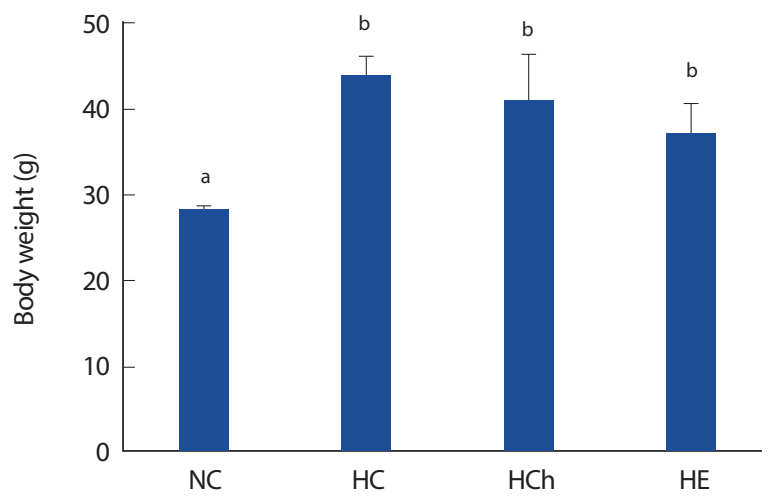

into a new tube, and then was allowed to stand at room temperature for 10 minutes after adding the same amount of isopropanol (Sigma, USA) into this supernatant solution, and it was centrifuged $\left(13,000 \mathrm{rpm}, 4^{\circ} \mathrm{C}\right.$, 10 minutes). 70\% ethanol of $1 \mathrm{~mL}$ was added on RNA pellet formed on the bottom of tube by centrifugation, and the pellet was washed twice (4,500 rpm, $4^{\circ} \mathrm{C}, 5$ minutes). If the RNA pellet was completely dried, the RNA pellet was dissolved by adding the $0.01 \%$ DEPC-treated distilled water of $30 \mu \mathrm{L}$. The array of forward and reverse primer is the same as shown in Table 3. The amplification was performed in a total volume of $20 \mu \mathrm{L}$, which included $2 \mu \mathrm{L}$ of cDNA, $1 \mu \mathrm{L}$ of each primer $(10 \mathrm{pmol} / \mu \mathrm{L})$, and $16 \mu \mathrm{L}$ of DEPC (Diethyl pyrocarbonate) water.

\section{Statistical methods}

Statistical analysis of the data was performed by SPSS Version 22.0 using one-way ANOVA with LSD post-hoc tests. Statistical significance was defined as $\alpha=.05$.

\section{RESULTS}

\section{Body weight and muscle mass}

Fig. 1 shows body weight and muscle mass. The body weight of high fat diet groups ( $\mathrm{HC}, \mathrm{HCh}, \mathrm{HE})$ were significantly increased, compared to that of $\mathrm{NC}$ group ( $p<.05$, Fig. 1A). The muscle mass of HE was significantly increased compared to that of NC $(28.33 \pm 0.21 \mathrm{~g})$, HC (43.93 \pm $2.15 \mathrm{~g})$ and $\mathrm{HCh}(40.83 \pm 5.37 \mathrm{~g})$ groups $(p<.05$, Fig. 1B).

\section{Food and calorie intake}

Fig. 2 shows feed intake and calorie intake. The feed intake of HCh was significantly lower than that of NC, HC and HE groups $(p<.05$, Fig.

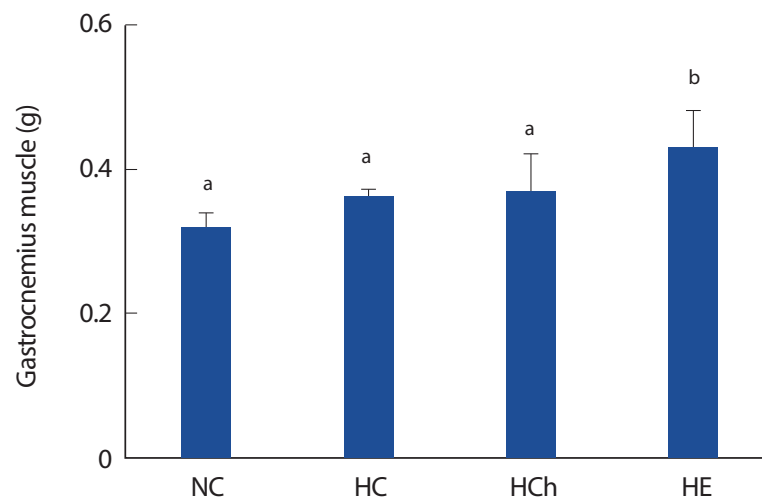

Fig. 1. The comparison of body and muscle weight among groups. (A) body weight; (B) gastrocnemius muscle weight. NC, normal diet control; HC, high fat diet control; $\mathrm{HCh}$, high fat diet with chrysin; $\mathrm{HE}$, high fat diet with exercise. Values represent mean \pm standard deviations. Different alphabet shows significant difference $(p<.05)$. 

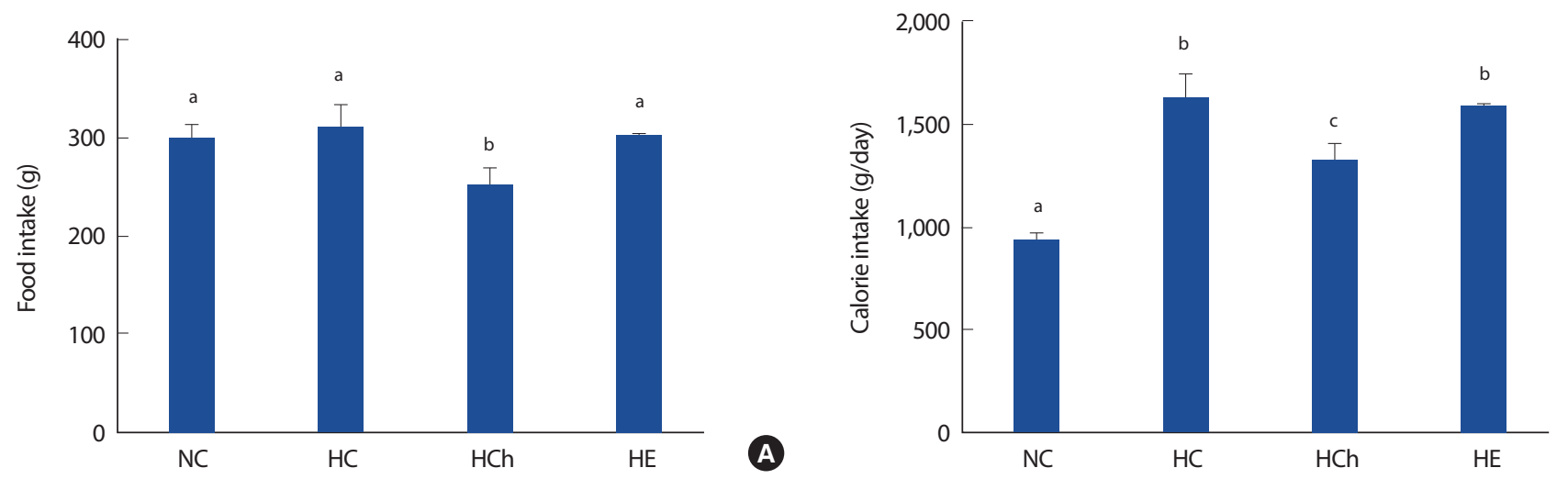

Fig. 2. The comparison of food and calorie intake among groups. (A) food intake; (B) calorie intake. NC, normal diet control; HC, high fat diet control; HCh, high fat diet with chrysin; $\mathrm{HE}$, high fat diet with exercise. Values represent mean \pm standard deviations. Different alphabet shows significant difference $(p<.05)$.
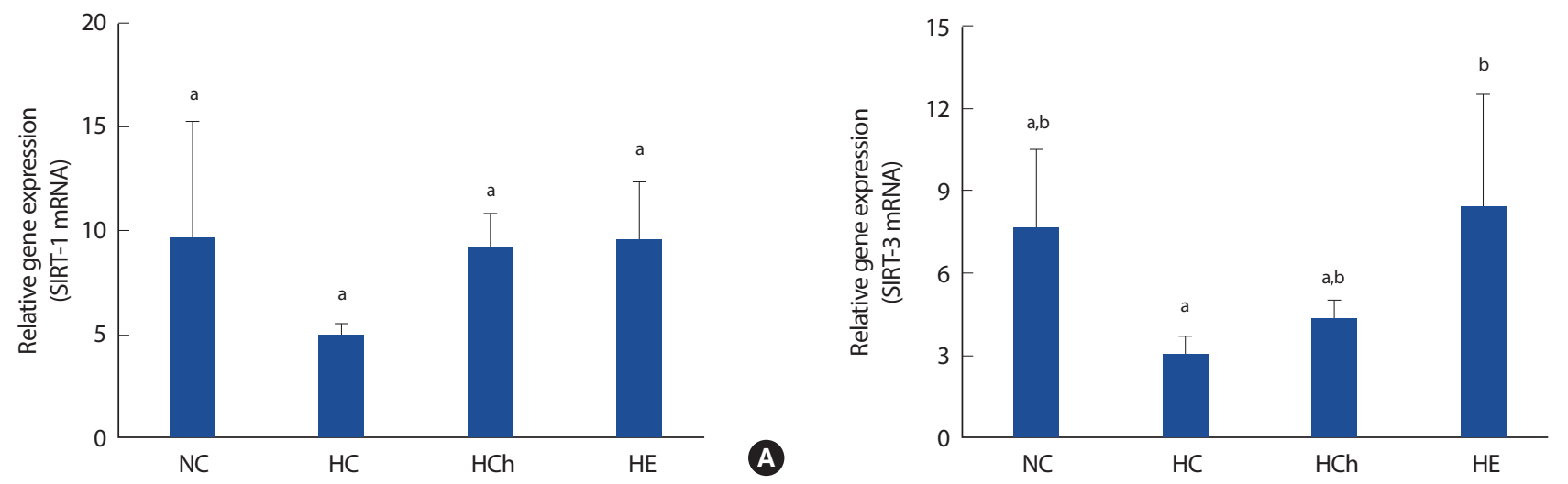

Fig. 3. The comparison of SIRT-1 and SIRT-3 mRNA among groups. (A) SIRT-1 mRNA; (B) SIRT-3 mRNA. NC, normal diet control; HC, high fat diet control; $\mathrm{HCh}$, high fat diet with chrysin; $\mathrm{HE}$, high fat diet with exercise. Values represent mean \pm standard deviations. Different alphabet shows significant difference $(p<.05)$.
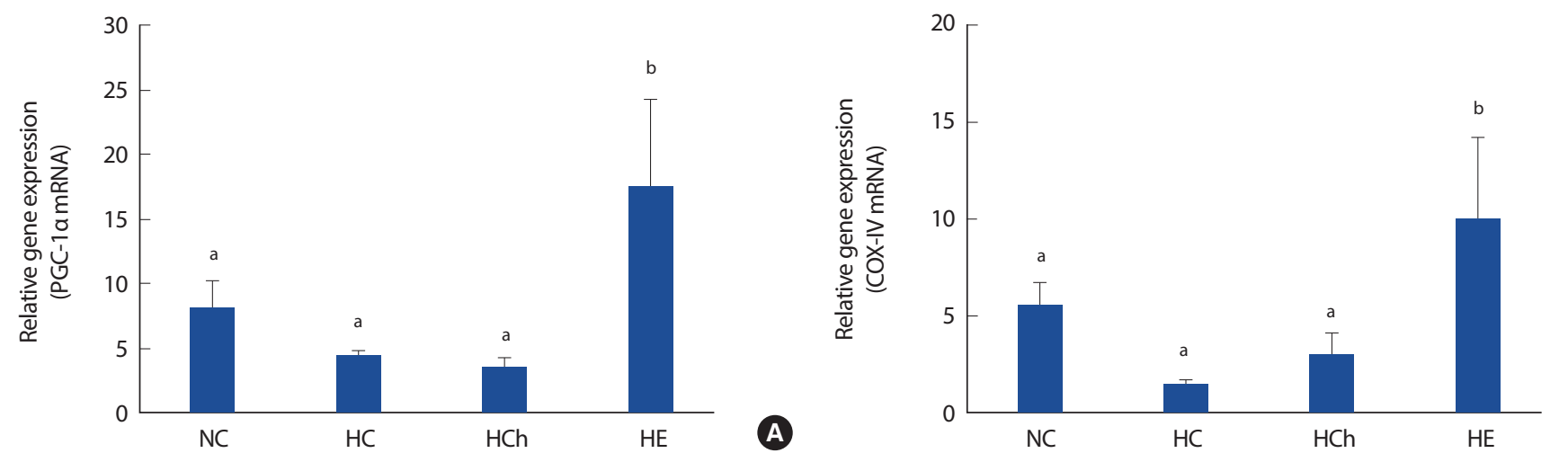

B

Fig. 4. The comparison of PGC-1a and COX-IV mRNA among groups. (A) PGC-1 a mRNA; (B) COX-IV mRNA. NC, normal diet control; HC, high fat diet control; $\mathrm{HCh}$, high fat diet with chrysin; $\mathrm{HE}$, high fat diet with exercise. Values represent mean \pm standard deviations. Different alphabet shows significant difference $(p<.05)$.

2A). The calorie intake of NC was most decreased, compared to that of HC, HCh and HE groups ( $p<.05$, Fig. 2B). Notably, the calorie intake of HCh was significantly lower than that of HC and HE groups $(p<.05$, Fig. 2B).

\section{SIRT-1 and SIRT-3 mRNA}

Fig. 3 shows the gene expression of SIRT-1 and SIRT-3 mRNA. There was no significance among all the groups in SIRT-1. However, the gene expression of SIRT-3 mRNA in HE group was significantly increased, 
compared to that in HC groups $(p<.05$, Fig. 3B). Also, the gene expression of SIRT-3 in NC group was a little increased but not significantly changed, compared to $\mathrm{HC}$ and $\mathrm{HCh}$ groups.

\section{PGC-1 $\alpha$ mRNA and COX-IV mRNA}

Fig. 4 shows the gene expression of PGC-1a and COX-IV mRNA. The gene expression of PGC-1a mRNA in HE group was significantly increased, compared to that in the other groups. Also, the gene expression of COX-IV mRNA in HE group was significantly increased, compared to the other groups ( $p<.05$, Fig. $4 \mathrm{~B})$. However, the COX-IV mRNA in $\mathrm{NC}$ group was not significantly increased, compared to that of HC group $(p<.05$, Fig. 4B).

\section{DISCUSSION}

In this study, we aimed to investigate the effects of aerobic exercise or chrysin supplementation on mitochondrial biogenesis (SIRT-1, SIRT-3, PGC-1a, COX-IV mRNA) in skeletal muscle of high fat diet-induced obese mice. A high fat diet is known to increase body weight and fat so that to make obese. Moderate exercise increases energy expenditure and has been recommended for the treatment of obesity [29]. However, the effect of polyphenols, such as chrysin for weight loss is not clear. In this study, we found that body weight was not significantly reduced by chrysin supplementation for 16 weeks in high fat-induced obese mice. This result is opposed to the fact that there was significant weight reduction with chrysin supplementation by both 20 or $40 \mathrm{mg} / \mathrm{kg} /$ day for 28 days [30]. Also, in previous results, the body weights of high fat-induced obesity mice were not significantly altered with 2 weeks chrysin supplementation by both 25 or $30 \mathrm{mg} / \mathrm{kg} /$ day, suggesting that chrysin shows no general adverse effects [31]. Even if the doses of chrysin supplementation was changed to $50 \mathrm{mg} / \mathrm{kg} /$ day in this study, the body weight was not significantly changed. It seems that the effect of chrysin supplementation is not clear, depending on the level of obesity, duration and doses of chrysin supplementation in obese mice. Also, the gastrocnemius muscle mass of HE group was significantly increased compared to that of other groups in this study. It seems that exercise has a more positive effect than chrysin to improve skeletal muscle weight. Thus, further study is needed to understand better with a various dosage and duration of chrysin supplementation on body weight and muscle mass.

Sirtuin is activated by NAD+-dependent deacetylases during the fasting condition in the brain, liver and kidney [15]. Further, it has been shown that sirtuin regulates metabolism and gene expression by stimulating the activation of SIRT-1 deacetylation. It even recovers damaged genes by activating PGC-1a, inhibiting weight gain and aging [32-34]. In previous studies, the expression of the SIRT-1 molecule was significantly reduced in the obese group compared to normal group [35]. Also, high fat diet-induced obese mice inhibited the activation of the SIRT-1 mRNA by the influence of white adipose tissue and metabolic dysfunction of the muscle tissue.

In this study, the SIRT-1 mRNA was not significantly changed in all the groups. Choi et al. [36] reported that chrysin supplementation increased AMPK activation but there are only a few studies comparing the effects on SIRT-1 activation. However, there was a tendency that the expression of SIRT-1 mRNA of HCh group were higher by $88 \%$ than that of HC group. Therefore, chrysin supplementation seems to have a positive effect on the activation of skeletal muscle SIRT-1 in high fat diet-induced obese mice. However, it is difficult to discuss the results of this study due to the lack of previous studies, and more studies will be needed in the future.

SIRT-3 is expressed in the mitochondria of the brain, heart, liver, adipose and skeletal muscle [37] and may be increased in AMP/ATP ratio, AMPK activation and regulate oxidative phosphorylation of mitochondria $[38,39]$. However, Lanza et al. [15] found that SIRT-3 protein and number of mitochondria are less expressed in sedentary individuals, and chronic high-fat diet inhibits SIRT-3 protein expression and induces hyperacetylation of mitochondrial protein [40]. Several previous studies have reported that aerobic exercise increases the expression of SIRT-3 in skeletal muscle $[13,14,41]$. Gurd et al. [42] reported that the expression of SIRT-3, PGC-1a by treadmill running and SIRT-3 protein in the skeletal muscle were increased by exercise and dietary restriction [13]. In human studies, the SIRT-3 expression in skeletal muscle was also increased by aerobic exercise [15].

In this study, there was no significance among $\mathrm{NC}, \mathrm{HC}$ and $\mathrm{HCh}$ groups, it means that high fat diet-induced obesity did not affect to the gene expression of SIRT-3. However, there was a tendency that the expression of SIRT-3 mRNA of NC group were higher than that of HC group. This result is a little similar to the results of previous studies [40]. Therefore, high-fat diet may have a negative effect on SIRT-3 activation of skeletal muscle in high fat diet-induced obese mice. In this study, the expression of skeletal muscle SIRT-3 mRNA of HE group was significantly increased compared to that of HC group. These results are consistent with the results of previous studies $[13,14,41,42]$. Therefore, it is con- 
sidered that the aerobic exercise has a positive effect on the SIRT-3 activation of skeletal muscle in high fat diet-induced obese mice.

Choi et al. [36] reported that chrysin supplementation increased the activation of AMPK, but studies on chrysin and SIRT-3 activation were not well known. In this study, there was no significant difference on expression of the skeletal muscle SIRT-3 mRNA in the NC, HC and HCh group. Therefore, further research will be needed.

Excessive fat accumulation or obesity is a major cause of mitochondrial dysfunction and reducing proteins such as mitochondrial biogenesis. It also cause skeletal muscle mitochondrial dysfunction by reducing proteins associated with PGC-1a that act on mitochondrial biogenesis and oxidative phosphorylation [43]. Several previous studies have reported decreased PGC-1a expression and mitochondrial function in skeletal muscle of high fat-induced obese mice [44-46]. Also, the expression of PGC-la was significantly lower in obese group than in normal group [35]. Decreased expression of PGC-1a is reduced exercise adaptability and caused acute inflammation and mitochondrial muscle disease [47,48].

In this study, there was no significant difference on expression of skeletal muscle PGC-1a mRNA among NC, HC and HCh group. However, the expression of skeletal muscle PGC-1a mRNA in HE group was significantly higher than that in other groups. It seems that high-fat diet is considered to have a negative effect on the PGC-1a activation of skeletal muscle in high fat-induced obese mice. However, the study of the effect of chrysin on PGC-la mRNA is needed further to understand better.

COX-IV protein plays an important role in aerobic exercise capacity by involved in the regulation of mitochondrial oxiative phosphorylation [16-18] and COX-IV is used as an indicator of aerobic exercise performance because it is controlled by PGC-1 $a$ that regulates mitochondrial biogenesis and function [19]. In this study, there was no significant difference of expression of skeletal muscle COX-IV mRNA among NC, HC and HCh group. These results are considered that COX-IV expression has been caused by the decrease of PGC-la expression. Also, these results are a little similar to the results of previous studies [19]. Therefore, $\mathrm{HC}$ group is considered to have a negative effect on COX-IV activation of skeletal muscle in high fat-induced obese mice.

Several previous studies have reported acute high-intensity cycle exercise significantly increased the protein levels of skeletal muscle PGC-1a and COX-IV [49,50]. Short et al. [18] reported that levels of PGC-1a and COX-IV mRNA were increased after 16 weeks of aerobic exercise and Greene et al. [51] reported that the protein levels of AMPK, PGC-1a and COX-IV which are closely related to mitochondrial biogenesis were sig- nificantly increased 12 weeks of moderate intensity exercise. In this study, HE group was significantly increased the expression of skeletal muscle COX-IV mRNA comprared to the HC group. Therefore, aerobic exercise is considered to have a positive effect on the activation of skeletal muscle COX-IV in high fat-induced obese mice.

In this study, HCh group showed no significant difference in the expression of skeletal muscle COX-IV mRNA compared to the HC group. Although these results are in contrast to the results of Scarpulla et al. [52], it seems that the expression of COX-IV was not affected because the expression of PGC-la had not been activated. Therefore, chrysin supplementation is considered to have no effect on the expression of skeletal muscle COX-IV in the skeletal muscle of high fat diet-induced obese mice.

\section{CONCLUSION}

Taken together, in this study, there were no significant effect of chrysin supplementation on the body weight and mitochondria biogenesis markers compared to aerobic exercise. It means that the effect of chrysin supplementation was not enough to reduce body weight and to activate mitochondrial biogenesis whereas aerobic exercise training had a positive effect to reduce body weight and improve mitochondria biogenesis gene activation. In conclusion, aerobic exercise training was more effective than chrysin supplementation to increase mitochondrial biogenesis markers in high fat diet-induced obese mice. Furthermore, aerobic exercise has a kind of medicine to ameliorate high fat diet-induced metabolic complication. However, the effect of chrysin supplementation should be researched further with a variety of doses and duration.

\section{ACKNOWLEDGMENT}

This work was supported by Chugnam National University (2018). All experiments were approved by the Animal Care and Use Committee at the Chungnam National University (CNU-00494).

\section{CONFLICT OF INTEREST}

No potential conflict of interest relevant to this article was reported.

\section{REFERENCES}

1. Borg ML, Omran SF, Weir J, Meikle PJ, Watt MJ. Consumption of a 
high-fat diet, but not regular endurance exercise training, regulates hypothalamic lipid accumulation in mice. J Physiol. 2012;590(17):4377-89.

2. Park HG, Lee YR, Jun JK, Lee WL. Exercise training is more effective than resveratrol supplementation on alleviation of inflammation in peritoneal macrophages of high fat diet mice. J Exerc Nutr Biochem. 2014;18(1):79

3. Patti ME, Butte AJ, Crunkhorn S, Cusi K, Berria R, et al. Coordinated reduction of genes of oxidative metabolism in humans with insulin resistance and diabetes: Potential role of PGC1 and NRF1. PNAS. 2003;100(14):8466-71.

4. Wilson FH, Hariri A, Farhi A, Zhao H, Petersen KF, et al. A cluster of metabolic defects caused by mutation in a mitochondrial tRNA. Science. 2004;306(5699):1190-4.

5. Lowell BB, Shulman GI. Mitochondrial dysfunction and type 2 diabetes. Science. 2005;307(5708):384-7.

6. Johnson ML, Robinson MM, Nair KS. Skeletal muscle aging and the mitochondrion. Trends Endocrinol Metab. 2013;24(5):247-56.

7. Lin J, Handschin C, Spiegelman BM. Metabolic control through the PGC-1 family of transcription coactivators. Cell Metab. 2005;1(6):36170.

8. Miura S, Tomitsuka E, Kamei Y, Yamazaki T, Kai Y, et al. Overexpression of peroxisome proliferator-activated receptor $\gamma$ co-activator- $1 \alpha$ leads to muscle atrophy with depletion of ATP. Am J Pathol. 2006; 169(4):1129-39.

9. Wende AR, Schaeffer PJ, Parker GJ, Zechner C, Han DH, et al. A role for the transcriptional coactivator PGC-1a in muscle refueling. J Biol Chem. 2007;282(50):36642-51.

10. Hood DA. Mechanisms of exercise-induced mitochondrial biogenesis in skeletal muscle. Appl Physiol Nutr Metab. 2009;34(3):465-72.

11. Irrcher I, Adhihetty PJ, Sheehan T, Joseph AM, Hood DA. PPAR $\gamma$ coactivator-1a expression during thyroid hormone-and contractile activity-induced mitochondrial adaptations. Am J Physiol Cell Physiol. 2003;284(6):C1669-C77.

12. Chabi B, Ljubicic V, Menzies KJ, Huang JH, Saleem A, et al. Mitochondrial function and apoptotic susceptibility in aging skeletal muscle. Aging Cell. 2008;7(1):2-12.

13. Palacios OM, Carmona JJ, Michan S, Chen KY, Manabe Y, et al. Diet and exercise signals regulate SIRT3 and activate AMPK and PGC-1a in skeletal muscle. Aging Cell. 2009;1(9):771.

14. Hokari F, Kawasaki E, Sakai A, Koshinaka K, Sakuma K, et al. Muscle contractile activity regulates Sirt3 protein expression in rat skeletal muscles. J Appl Physiol. 2010;109(2):332-40.

15. Lanza IR, Short DK, Short KR, Raghavakaimal S, Basu R, et al. Endurance exercise as a countermeasure for aging. Diabetes. 2008;57(11): 2933-42.

16. Burgomaster KA, Cermak NM, Phillips SM, Benton CR, Bonen A, et al. Divergent response of metabolite transport proteins in human skeletal muscle after sprint interval training and detraining. Am J Physiol Regul Integr Comp Physiol. 2007;292(5):1970-6.

17. Geng T, Li P, Okutsu M, Yin X, Kwek J, et al. PGC-1 $\alpha$ plays a functional role in exercise-induced mitochondrial biogenesis and angiogenesis but not fiber-type transformation in mouse skeletal muscle. Am J Physiol Cell Physiol. 2009;298(3):572-9.

18. Short KR, Vittone JL, Bigelow ML, Proctor DN, Rizza RA, et al. Impact of aerobic exercise training on age-related changes in insulin sensitivity and muscle oxidative capacity. Diabetes. 2003;52(8):1888-96.

19. Olesen J, Kiilerich K, Pilegaard H. PGC-1a-mediated adaptations in skeletal muscle. Pflugers Arch. 2010;460(1):153-62.

20. Manach C, Scalbert A, Morand C, Rémésy C, Jiménez L. Polyphenols: food sources and bioavailability. Am J Clin Nutr. 2004;79(5):727-47.

21. Rapta P, Mišík V, Staško A, Vrábel I. Redox intermediates of flavonoids and caffeic acid esters from propolis: an EPR spectroscopy and cyclic voltammetry study. Free Radic Biol Med. 1995;18(5):901-8.

22. Williams CA, Harborne JB, Newman M, Greenham J, Eagles J. Chrysin and other leaf exudate flavonoids in the genus Pelargonium. Phytochemistry. 1997;46(8):1349-53.

23. Khan R, Khan AQ, Qamar W, Lateef A, Tahir M, et al. Chrysin protects against cisplatin-induced colon. toxicity via amelioration of oxidative stress and apoptosis: probable role of p38MAPK and p53. Toxicol Appl Pharmacol. 2012;258(3):315-29.

24. Cherkaoui Tangi K, Lachkar M, Wibo M, Morel N, Gilani A, et al Pharmacological studies on hypotensive, diuretic and vasodilator activities of chrysin glucoside from Calycotome villosa in rats. Phytother Res. 2008;22(3):356-61.

25. Song MY, Jeong GS, Kwon KB, Ka SO, Jang HY, et al. Sulfuretin protects against cytokine-induced $\beta$-cell damage and prevents streptozotocin-induced diabetes. Exp Mol Med. 2010;42(9):628.

26. Tahir M, Sultana S. Chrysin modulates ethanol metabolism in Wistar rats: a promising role against organ toxicities. Alcohol Alcohol. 2011; 46(4):383-92.

27. Pushpavalli G, Veeramani C, Pugalendi KV. Influence of chrysin on hepatic marker enzymes and lipid profile against D-galactosamine-in- 
duced hepatotoxicity rats. Food Chem Toxicol. 2010;48(6):1654-9.

28. Schefer V, Talan MI. Oxygen consumption in adult and AGED C57BL/ $6 \mathrm{~J} \mathrm{mice} \mathrm{during} \mathrm{acute} \mathrm{treadmill} \mathrm{exercise} \mathrm{of} \mathrm{different} \mathrm{intensity.} \mathrm{Exp} \mathrm{Geron-}$ tol. 1996;31(3):387-92.

29. King GA, Fitzhugh E, Bassett Jr D, McLaughlin J, Strath SJ, et al. Relationship of leisure-time physical activity and occupational activity to the prevalence of obesity. Int J Obes. 2001;25(5):606.

30. Kandhare AD, Shivakumar V, Rajmane A, Ghosh P, Bodhankar SL. Evaluation of the neuroprotective effect of chrysin via modulation of endogenous biomarkers in a rat model of spinal cord injury. J Nat Med. 2014;68(3):586-603.

31. Feng X, Qin H, Shi Q, Zhang Y, Zhou F, et al. Chrysin attenuates inflammation by regulating M1/M2 status via activating PPAR $\gamma$. Biochem Pharmacol. 2014;89(4):503-14.

32. Baur JA. Biochemical effects of SIRT1 activators. Biochim. Biochim Biophys Acta. 2010;1804(8):1626-34.

33. Lin J, Wu H, Tarr PT, Zhang CY, Wu Z, et al. Transcriptional co-activator PGC-1 1 a drives the formation of slow-twitch muscle fibres. Nature. 2002;418(6899):797.

34. Lagouge M, Argmann C, Gerhart-Hines Z, Meziane H, Lerin C, et al. Resveratrol improves mitochondrial function and protects against metabolic disease by activating SIRT1 and PGC-1a. Cell. 2006;127(6):110922.

35. Lopez-Lluch G, Hunt N, Jones B, Zhu M, Jamieson H, et al. Calorie restriction induces mitochondrial biogenesis and bioenergetic efficiency. PNAS. 2006;103(6):1768-73.

36. Choi JH, Yun JW. Chrysin induces brown fat-like phenotype and enhances lipid metabolism in 3T3-L1 adipocytes. Nutrition. 2016;32(9): 1002-10.

37. Lombard DB, Alt FW, Cheng HL, Bunkenborg J, Streeper RS, et al. Mammalian Sir2 homolog SIRT3 regulates global mitochondrial lysine acetylation. Mol Cell Biol. 2007;27(24):8807-14.

38. North BJ, Sinclair DA. Sirtuins: a conserved key unlocking AceCS activity. Trends Biochem Sci. 2007;32(1):1-4.

39. Hallows WC, Lee S, Denu JM. Sirtuins deacetylate and activate mammalian acetyl-CoA synthetases. PNAS. 2006;103(27):10230-5.

40. Hirschey MD, Shimazu T, Jing E, Grueter CA, Collins AM, et al. SIRT3 deficiency and mitochondrial protein hyperacetylation accelerate the development of the metabolic syndrome. Mol Cell. 2011;44(2):177-90.

41. Kong X, Wang R, Xue Y, Liu X, Zhang H, et al. Sirtuin 3, a new target of PGC-1a, plays an important role in the suppression of ROS and mitochondrial biogenesis. PLoS One. 2010;5(7):e11707.

42. Gurd BJ, Holloway GP, Yoshida Y, Bonen A. In mammalian muscle, SIRT3 is present in mitochondria and not in the nucleus; and SIRT3 is upregulated by chronic muscle contraction in an adenosine monophosphate-activated protein kinase-independent manner. Metabolism. 2012;61(5):733-41.

43. Jelenik T, Roden M. Mitochondrial plasticity in obesity and diabetes mellitus. Antioxid Redox Signal. 2013;19(3):258-68.

44. Mensink M, Hesselink M, Russell A, Schaart G, Sels J, et al. Improved skeletal muscle oxidative enzyme activity and restoration of PGC-1a and $\mathrm{PPAR} \beta / \delta$ gene expression upon rosiglitazone treatment in obese patients with type 2 diabetes mellitus. Int J Obes. 2007;31(8):1302.

45. Samocha Bonet D, Dixit V, Kahn C, Leibel R, Lin X, et al. Metabolically healthy and unhealthy obese-the 2013 Stock Conference report. Obes Rev. 2014;15(9):697-708.

46. Laker RC, Lillard TS, Okutsu M, Zhang M, Hoehn KL, et al. Exercise prevents maternal high-fat diet-induced hypermethylation of the Pgcla gene and age-dependent metabolic dysfunction in the offspring. Diabetes. 2014;63(5):1605-11.

47. Handschin C, Spiegelman BM. Peroxisome proliferator-activated receptor $\gamma$ coactivator 1 coactivators, energy homeostasis, and metabolism. Endocr Rev. 2006;27(7):728-35.

48. Handschin C, Choi CS, Chin S, Kim S, Kawamori D, et al. Abnormal glucose homeostasis in skeletal muscle-specific PGC-1a knockout mice reveals skeletal muscle-pancreatic $\beta$ cell crosstalk. J Clin Inves. 2007;117(11):3463-74.

49. Cartoni R, Léger B, Hock MB, Praz M, Crettenand A, et al. Mitofusins 1/2 and ERRa expression are increased in human skeletal muscle after physical exercise. J Physiol. 2005;567(1):349-58.

50. Cobley JN, Bartlett J, Kayani A, Murray S, Louhelainen J, et al. PGCla transcriptional response and mitochondrial adaptation to acute exercise is maintained in skeletal muscle of sedentary elderly males. Biogerontology. 2012;13(6):621-31.

51. Greene NP, Fluckey JD, Lambert BS, Greene ES, Riechman SE, et al. Regulators of blood lipids and lipoproteins? PPAR $\delta$ and AMPK, induced by exercise, are correlated with lipids and lipoproteins in overweight/obese men and women. Am J Physiol Endocrinol Metab. 2012; 303(10):1212-21.

52. Scarpulla RC. Metabolic control of mitochondrial biogenesis through the PGC-1 family regulatory network. Biochim Biophys Acta. 2011; 1813(7):1269-78. 